\title{
Associations of sclerostin with carotid artery atherosclerosis and all-cause mortality in Chinese patients undergoing maintenance hemodialysis
}

\author{
Aiqun Chen ${ }^{1}$, Ying Sun ${ }^{1}$, Ju Cui ${ }^{2}$, Ban Zhao ${ }^{1}$, Haitao Wang ${ }^{1}$, Xianguang Chen ${ }^{1}$ and Yonghui Mao ${ }^{1 *}$
}

\begin{abstract}
Background: Previous clinical studies found inconsistent relationship between circulating sclerostin levels and treatment outcome in patients undergoing maintenance hemodialysis (MHD). Therefore, this study aimed to assess the associations of sclerostin with carotid artery atherosclerosis and all-cause mortality in Chinese patients undergoing MHD.

Methods: This retrospective study assessed 84 patients undergoing MHD at the Nephrology Department of Beijing Hospital from January to April 2012, with a median follow-up of 61.2 months (range: 11.5 to 63 months). Carotid artery intima-media thicknesses (CIMTs) and atherosclerotic plaques were measured by B-mode Doppler ultrasound at baseline. Blood samples were collected for measuring serum sclerostin and soluble klotho (s-klotho) levels. The associations of sclerostin levels with carotid artery atherosclerosis was evaluated by correlation methods. Predictive factors of mortality were assessed by multivariate COX regression.
\end{abstract}

Results: Baseline serum sclerostin averaged $162.01 \mathrm{pmol} / \mathrm{L}$, with an interquartile range of 121.69 to $225.22 \mathrm{pmol} / \mathrm{L}$, while CIMT values were $1.35 \pm 0.39 \mathrm{~mm}$. Carotid artery atherosclerotic plaques were detected in 68 subjects (81\%). Subjects with sclerostin levels above the median value had higher CIMT $(p=0.038)$ and higher prevalence of atherosclerotic plaque $(p=0.025)$. During follow-up, 27 patients died; Kaplan-Meier curves indicated that subjects with high sclerostin levels (above the median value at baseline) had shorter survival (log rank $p=0.011$ ). In multivariate COX regression analysis, serum sclerostin (HR, 1.095; 95\% confidence interval [CI] 1.022-1.174, $p=0.010$ ) and albumin ( $\mathrm{HR}, 0.742 ; 95 \% \mathrm{Cl} 0.612-0.900, p=0.002)$ levels were independent predictors of all-cause mortality.

Conclusions: Sclerostin is positively associated with CIMT. In addition, patients with low baseline serum sclerostin undergoing MHD show better survival.

Keywords: Carotid artery intima-media thickness, Maintenance hemodialysis, Mortality, Sclerostin

\section{Background}

Cardiovascular disease is the leading cause of mortality in patients undergoing maintenance hemodialysis (MHD), with a prevalence 3-10 times higher in such patients compared with the general population [1, 2]. Higher cardiovascular risk in patients undergoing MHD is partly explained by chronic kidney disease-mineral

\footnotetext{
* Correspondence: maoyonghui0214@bjhmoh.cn

${ }^{1}$ Department of Nephrology, Beijing Hospital, National Center of Gerontology, Beijing, People's Republic of China

Full list of author information is available at the end of the article
}

bone disorder (CKD-MBD), in which sclerostin plays an important role [3].

The Wnt- $\beta$-catenin pathway plays a crucial role in skeletal development and bone mass. Dysregulated Wnt- $\beta$-catenin pathway is also involved in cancer, aortic valve calcification, several bone-related phenotypes, and CKD-MBD $[4,5]$. Indeed, the Wnt-signaling pathway is involved in stimulating osteoblast proliferation, differentiation, and bone formation [6]. Sclerostin, the product of the SOST gene [7], is an antagonist of the Wnt pathway $[4,5]$ and is involved in the crosstalk among

(C) The Author(s). 2018 Open Access This article is distributed under the terms of the Creative Commons Attribution 4.0 International License (http://creativecommons.org/licenses/by/4.0/), which permits unrestricted use, distribution, and 
kidneys, bones, and vasculature [5]. Sclerostin is a soluble inhibitor of Wnt- $\beta$-catenin (canonical) signaling pathway, that reduces osteoblastogenesis and promotes osteoblast and osteocyte apoptosis thus exerting a powerful anti-anabolic effect [5]. Interestingly, Pelletier et al. [8] found that serum sclerostin levels are higher in CKD patients compared with the general population, and start to increase in CKD stage III. Sclerostin gradually increases as renal function declines, and is inversely correlated with glomerular filtration rate (GFR; calculated by insulin clearance) [8]. In addition to renal retention [9], higher sclerostin in CKD may also be related to enhanced production by bone cells $[3,10]$. Meanwhile, the Wnt-signaling pathway regulates vascular tissue development and endothelial cell differentiation, and is closely associated with atherosclerosis [11, 12]. Importantly, sclerostin was detected in non-uremic and uremic aortic valve calcification (AVC) and skin calciphylaxis tissues by immunohistochemistry (IHC) [1315]. The above findings suggest a role for sclerostin in cardiovascular disease.

Recently, Viaene et al. [16] and Drechsler et al. [17] demonstrated that high serum sclerostin levels are associated with improved survival in patients undergoing MHD. But other studies indicated that high serum sclerostin is associated with higher mortality in non-dialysis CKD and MHD patients [18-20]. Based on these discrepant findings, the present study aimed to assess whether carotid artery atherosclerosis is associated with sclerostin in patients undergoing MHD. Since treatment outcome may depend on patient characteristics and follow up duration, we also determined the association of sclerostin and all-cause mortality in Chinese patients undergoing MHD.

\section{Methods}

\section{Study population}

The present study was a secondary analysis of a cross-sectional study conducted in 2012 that assessed 88 patients undergoing MHD [21], whose baseline serum samples were stored at $-80{ }^{\circ} \mathrm{C} ; 4$ samples were lost. Therefore, this study retrospectively assessed 84 patients undergoing MHD at the Nephrology Department of Beijing Hospital in January-April 2012. Inclusion criteria were: age $\geq 18$ years, dialysis vintage $\geq 3$ months, KT/V (urea nitrogen removal index) $>1.2$, and availability of serum samples for sclerostin measurement. Patients with malignancies, autoimmune diseases, active liver disease, fractures, and/or acute and chronic infections were excluded. All subjects underwent hemodialysis for $4 \mathrm{~h}$ with standard bicarbonate dialysate (3 times per week), with a few subjects submitted to hemofiltration 1-2 times monthly. The dialyzer membrane was polymethylmethacrylate (P-MMA) or polysulfone (PS), with an area of
1.4-1.6 $\mathrm{m}^{2}$. Heparin anticoagulation was employed, with vascular access via an arteriovenous fistula. The blood flow rate was $200-300 \mathrm{~mL} / \mathrm{min}$, for a dialysate flow of $500 \mathrm{~mL} / \mathrm{min}$. The study was performed according to the Declaration of Helsinki and approved by the ethics committee of Beijing Hospital (ethical approval number: 2016BJYYEC-110-01). Written informed consent was obtained from all patients.

\section{Clinical and biochemical parameters}

Age, sex, history of diabetes, and ESRD causes were collected by reviewing medical records. Blood samples were collected at baseline, before hemodialysis initiation. We used the first hemodialysis session of a given patient after January 2012 and each patient was assessed once. Serum urea, creatinine, uric acid, total serum calcium, phosphorus, albumin, triglycerides, total cholesterol, low-density lipoprotein cholesterol (LDL-C), high-density lipoprotein cholesterol (HDL-C), alkaline phosphatase (AP), high-sensitivity C-reactive protein (hs-CRP), and hemoglobin amounts were measured by standard laboratory methods. All routine assays were performed at the central laboratory of the hospital. Then, serum samples were stored at $-80{ }^{\circ} \mathrm{C}$ until further analysis. Soluble klotho (s-klotho) levels were assessed in August 2012 with a specific enzyme-linked immunosorbent assay (ELISA) kit (R\&D Systems, Inc., Minneapolis, MN, USA), according to the manufacturer's instructions. The range of the assay standard curve is 8 to $150 \mathrm{U} / \mathrm{L}$. Sclerostin amounts were measured in October 2016 with an ELISA kit from Biomedica (Austria) based on the manufacturer's protocol. The intra-assay and inter-assay coefficients of variation are, according to the manufacturer, $\leq 7 \%$ and $\leq 10 \%$, respectively. The median sclerostin value in apparently healthy individuals is $24.14 \mathrm{pmol} / \mathrm{L}$. The range of the assay standard curve is 0 to $240 \mathrm{pmol} / \mathrm{L}$. All ELISAs and non-routine assays were performed by the same operator.

\section{B-mode and Doppler ultrasound of the common carotid arteries}

B-mode and Doppler ultrasound of the common carotid arteries was performed at baseline. With the patient in the supine position with the head tilted backward, the common carotid arteries were detected bilaterally using color Doppler ultrasound at a frequency of $5-10 \mathrm{MHz}$ (Philips model IU-22). Bilateral images of the common carotid arteries were obtained by an experienced sonographer, with each measurement repeated twice. The CIMT was obtained just before the carotid artery bulb, and defined as the vertical distance between the lumen-intima and media-adventitia interfaces on the posterior wall of the carotid artery. The results were expressed as maximum values obtained for the left and right arteries. Atherosclerotic plaque was defined as CIMT exceeding $1.5 \mathrm{~mm}$ [22]. 


\section{Follow-up and outcome analysis}

All patients were followed-up until April 30, 2017. The primary endpoint was all-cause mortality. The time and cause of death were also recorded for each deceased patient.

\section{Statistical analyses}

Statistical analyses were performed with the SPSS 20.0 software. Normally distributed variables were expressed as mean \pm standard deviation (SD), and non-normally distributed variables as median with 25th and 75th percentiles. Differences between groups were compared by Student's t test or Mann-Whitney U test. Categorical data were presented as percentage, and assessed by the Chi-square test.
The Spearman method was used to estimate the correlation between sclerostin and other parameters. The Kaplan -Meier method was used to assess all-cause mortality. The associations of baseline indices with patient survival were assessed by Cox multivariate regression analysis. $P<0.05$ was considered statistically significant.

\section{Results}

\section{Patient baseline characteristics}

The clinical and demographic characteristics of the cohort are shown in Table 1. The original dataset of the study is provided in Additional file 1. A total of 84 sub-

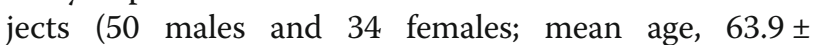

Table 1 Demographic characteristics of all patients, and comparisons between the high and low sclerostin groups

\begin{tabular}{|c|c|c|c|c|}
\hline Variable & $\begin{array}{l}\text { All patients } \\
n=84\end{array}$ & $\begin{array}{l}\mathrm{Scl}<162.01 \mathrm{pmol} / \mathrm{L} \\
(n=42)\end{array}$ & $\begin{array}{l}\mathrm{Scl}>162.01 \mathrm{pmol} / \mathrm{L} \\
(n=42)\end{array}$ & $P$ value \\
\hline Male/female & $50 / 34$ & $22 / 20$ & $28 / 14$ & 0.133 \\
\hline Age (years) & $63.9 \pm 11.5$ & $61.5 \pm 12.6$ & $66.2 \pm 10.0$ & 0.062 \\
\hline Diabetes, n (\%) & $28(33.33)$ & $13(30.95)$ & $15(35.71)$ & 0.409 \\
\hline Cardiovascular history, n (\%) & $44(52.4)$ & $22(52.4 \%)$ & $22(52.4 \%)$ & 1.000 \\
\hline $\mathrm{BMI}\left(\mathrm{kg} / \mathrm{m}^{2}\right)$ & $23.59 \pm 3.32$ & $23.57 \pm 3.85$ & $23.61 \pm 2.73$ & 0.953 \\
\hline Systolic BP (mmHg) & $149 \pm 19$ & $146 \pm 17$ & $150 \pm 20$ & 0.374 \\
\hline Diastolic BP (mmHg) & $79 \pm 11$ & $79 \pm 13$ & $79 \pm 9$ & 0.898 \\
\hline Dialysis vintage, months & $57.6(27.3-85.5)$ & $51.5(21.2-84.4)$ & $62.3(38.7-92.1)$ & 0.207 \\
\hline CIMT (mm) & $1.35 \pm 0.39$ & $1.26 \pm 0.38$ & $1.44 \pm 0.39$ & 0.038 \\
\hline Plaque, n (\%) & $68(80.95)$ & $30(71.43)$ & $38(90.48)$ & 0.025 \\
\hline Sclerostin (pmol/L) & $162.01(121.69-225.22)$ & $121.75(91.03-145.44)$ & $225.01(194.08-250.27)$ & $<0.001$ \\
\hline s-klotho $(U / L)$ & $41.27(28.12-72.27)$ & 44.88 (29.90-77.19) & $39.37(26.57-51.70)$ & 0.156 \\
\hline PTH $(10-69 \mathrm{pg} / \mathrm{mL})^{\mathrm{a}}$ & $485.50(255.75-730.50)$ & $498.00(260.25-843.50)$ & $450.50(245.75-705.75)$ & 0.691 \\
\hline Hemoglobin $(120-160 \mathrm{~g} / \mathrm{L})^{a}$ & $114.00(101.75-123.75)$ & $116.00(100.00-125.25)$ & $113.50(106.00-121.25)$ & 0.585 \\
\hline Albumin $(34-48 \mathrm{~g} / \mathrm{L})^{a}$ & $41.00(39.25-42.00)$ & $41(39-42)$ & $41(40-42)$ & 0.521 \\
\hline Creatinine $(59-104 \mu \mathrm{mol} / \mathrm{L})^{\mathrm{a}}$ & $922.08 \pm 258.78$ & $917.55 \pm 298.97$ & $926.62 \pm 214.81$ & 0.847 \\
\hline Uric acid $(208-428 \mu \mathrm{mol} / \mathrm{L})^{\mathrm{a}}$ & $392.27 \pm 84.85$ & $407.81 \pm 91.01$ & $376.74 \pm 76.13$ & 0.093 \\
\hline Phosphate $(0.92-1.62 \mathrm{mmol} / \mathrm{L})^{\mathrm{a}}$ & $1.80 \pm 0.53$ & $1.77 \pm 0.52$ & $1.84 \pm 0.54$ & 0.547 \\
\hline Calcium $(2.03-2.54 \mathrm{mmol} / \mathrm{L})^{\mathrm{a}}$ & $2.20 \pm 0.22$ & $2.18 \pm 0.22$ & $2.21 \pm 0.23$ & 0.567 \\
\hline Cholesterol $(<5.2 \mathrm{mmol} / \mathrm{L})^{\mathrm{a}}$ & $4.21 \pm 0.92$ & $4.29 \pm 1.00$ & $4.13 \pm 0.83$ & 0.440 \\
\hline $\operatorname{LDL}-\mathrm{C}(<3.2 \mathrm{mmol} / \mathrm{L})^{\mathrm{a}}$ & $2.31 \pm 0.66$ & $2.41 \pm 0.70$ & $2.20 \pm 0.62$ & 0.147 \\
\hline $\mathrm{HDL}-\mathrm{C}(>1.04 \mathrm{mmol} / \mathrm{L})^{\mathrm{a}}$ & $1.02 \pm 0.27$ & $1.00 \pm 0.25$ & $1.05 \pm 0.30$ & 0.379 \\
\hline Alkaline phosphatase $(30-130 \mathrm{U} / \mathrm{L})^{\mathrm{a}}$ & $103.00(75.50-135.50)$ & $109.50(76.50-159.50)$ & $99.00(74.75-118.75)$ & 0.263 \\
\hline $\mathrm{Kt} / \mathrm{N}$ & $1.32 \pm 0.31$ & $1.34 \pm 0.32$ & $1.29 \pm 0.29$ & 0.414 \\
\hline hs-CRP (0-3 mg/L) & $3.18(1.65-6.68)$ & $3.42(1.86-6.25)$ & $2.31(1.49-7.22)$ & 0.351 \\
\hline Anti-hypertensive drug $(n, \%)$ & $71(84.5)$ & $35(83.3)$ & $36(85.7)$ & 0.763 \\
\hline Statin $(n, \%)$ & $20(23.8)$ & $8(19.1)$ & $12(28.6)$ & 0.306 \\
\hline Calcium-based phosphate binders (n, \%) & $63(75.0)$ & $30(71.4)$ & $33(78.6)$ & 0.450 \\
\hline Calcitriol (n, \%) & $49(58.3)$ & $27(64.3)$ & $22(52.4)$ & 0.268 \\
\hline
\end{tabular}

${ }^{a}$ Normal reference values are shown between brackets. Note: no reference value for $s$-Kloto is provided by the kit's manufacturer

Normally distributed variables are mean \pm standard deviation; non-normally distributed variables are median with 25 and $75 \%$ interquartile ranges in parentheses. CIMT carotid artery intima-media thickness, IPTH intact parathyroid hormone, sKlotho soluble klotho, LDL-C low-density lipoprotein cholesterol, HDL-C high-density lipoprotein cholesterol, $\mathrm{Hs}$-CRP high-sensitivity C-reactive protein 
11.5 years; age range, 39-87 years) were enrolled, including 28 who had diabetes. ESRD causes were chronic glomerulonephritis $(n=34,40.5 \%)$, diabetic nephropathy $(n=20,23.8 \%)$, hypertensive renal disease $(n=10$, $11.9 \%)$, chronic interstitial nephritis $(n=10,11.9 \%)$, polycystic kidney disease $(n=7,8.3 \%)$, and other diseases $(n=3,3.6 \%)$.

Men had higher sclerostin levels compared with women (191.39 vs. $155.82 \mathrm{pmol} / \mathrm{L} ; p=0.031)$. Although males showed higher CIMT values in comparison with females, the difference was not statistically significant $(1.41 \pm$ 0.40 vs. $1.26 \pm 0.35 \mathrm{~mm}, p=0.062$ ). Diabetic subjects had higher CIMT values compared with patients without diabetes $(1.50 \pm 0.39$ vs. $1.28 \pm 0.37 \mathrm{~mm}, p=0.012)$. Sclerostin levels between the patients with and without diabetes were comparable (174.24 vs. $160.33 \mathrm{pmol} / \mathrm{L}$; median, $p=0.718)$.

\section{Differences between the high and low sclerostin groups}

Since the sclerostin levels were not normally distributed, non-parametric analyses were used and the subjects $(n=$ 84) were divided into two groups according to the median sclerostin level $(162.01 \mathrm{pmol} / \mathrm{L})$ into the "high" and "low" sclerostin groups, as in previous studies $[16,19]$. The high sclerostin group showed higher CIMT (1.44 \pm 0.39 vs. $1.26 \pm 0.38 \mathrm{~mm}, p=0.038)$ and higher prevalence of atherosclerotic plaques (90.48 vs. $71.43 \%, p=0.025)$, compared with the low sclerostin group (Table 1).

\section{Association of plasma sclerostin with demographic characteristics and clinical parameters}

There was a significant positive correlation between sclerostin and CIMT (Spearman rank $r=0.262 ; p=$ 0.016), and a negative association of sclerostin with s-klotho (Spearman rank $r=-0.217 ; p=0.047$ ). After adjustment for age, gender, and diabetes, sclerostin was still independently associated with CIMT $(\mathrm{OR}=1.161$, 95\%CI: $1.046-1.288, p=0.005)$. A positive correlation was obtained between sclerostin and age (Spearman rank $r=0.195 ; p=0.075$ ) although statistical significance was not reached. There were no significant associations of sclerostin with $\mathrm{PTTH}$ and AP.

\section{Differences between survivors and non-survivors}

During the follow-up period, 27 subjects died and 18 out of 27 deaths were cardiovascular disease-related; none was lost to follow-up or received kidney transplant. Non-survivors were older $(68.6 \pm 11.1$ vs. $61.6 \pm$ 11.1 years, $p=0.009$ ), had a higher prevalence of diabetes $(51.85$ vs. $24.56 \%, p=0.014)$, and showed higher CIMT ( $1.51 \pm 0.40$ vs. $1.27 \pm 0.37 \mathrm{~mm}, p=0.011)$, higher sclerostin levels $(217.30$ vs. $152.34 \mathrm{pmol} / \mathrm{L}, p=0.042)$, and lower uric acid amounts $(361.93 \pm 60.30 \mu \mathrm{mol} / \mathrm{L}$ vs. $406.65 \pm 91.25 \mu \mathrm{mol} / \mathrm{L}, \quad p=0.023)$, compared with survivors (Table 2). Meanwhile, non-survivors showed trends of higher prevalence of carotid artery atherosclerotic plaques ( 92.59 vs. $75.44 \%, p=0.053$ ) and lower albumin levels (40 vs. $41 \mathrm{~g} / \mathrm{L}$, median, $p=0.060$ ) compared with the survivor group (Table 2).

\section{Association of sclerostin with all-cause mortality}

The 84 patients were divided into two groups according to the median sclerostin level $(162.01 \mathrm{pmol} / \mathrm{L})$. Kaplan -Meier curves (Fig. 1) showed that the high sclerostin group had reduced survival (log rank $p=0.011)$ compared with the low sclerostin group. The follow-up ranged from 11.5 to 63 months (median, 61.2 months; IQR, 47.862.3 months). In the low and high sclerostin groups, 1-year survival was $100 \%$ and $97.6 \%$, respectively; 3-year survival was $88.1 \%$ and $71.4 \%$, respectively; and 5 -year survival was $80.1 \%$ and $54.8 \%$, respectively. The associations of all-cause death with various parameters were assessed by multivariate Cox regression analysis. Based on univariate analysis (Table 3 ), age, albumin, uric acid, sclerostin, CIMT, diabetes and history of cardiovascular disease $(p<$ $0.05)$ were included. The results indicated that serum sclerostin (HR, 1.095; 95\% confidence interval [CI] 1.022$1.174, p=0.010)$ and albumin (HR, 0.742; 95\%CI 0.612 $0.900, p=0.002)$ levels were independent predictors of all-cause mortality.

\section{Association of sclerostin with cardiovascular death}

Next, the associations of various indices with cardiovascular death were evaluated. Age $(p=0.004)$, diabetes $(p=$ $0.015)$, and CIMT $(p=0.001)$ showed significant associations in univariate analyses (Table 4), and were entered in the multivariate analysis. Interestingly, CIMT $(\mathrm{HR}=1.158$; $95 \% \mathrm{CI} 1.017-1.320 ; p=0.027)$ and age $(\mathrm{HR}=1.063$; $95 \%$ CI $1.011-1.118 ; p=0.016)$ were independent predictive factors of cardiovascular death in these patients.

\section{Discussion}

The association of serum sclerostin levels with survival in patients undergoing MHD remain unclear. This study revealed a positive correlation between sclerostin and CIMT, and patients with low serum sclerostin levels had improved survival. In addition, serum sclerostin and albumin levels were independent predictors of all-cause mortality in patients undergoing MHD.

Previous studies reported that serum sclerostin gradually increases from non-uremic controls without overt calcification-related cardiovascular disease to those with AVC, and from uremic patients without AVC to their counterparts with AVC [13, 15]. In uremia, vascular smooth muscle cells (VSMCs) are affected by calcium, phosphorus, stress, and other factors, and undergo osteogenic and/or chondrogenic differentiation, to form 
Table 2 Comparisons between the survivor and non-survivor groups

\begin{tabular}{|c|c|c|c|}
\hline & $\begin{array}{l}\text { Non-survival group } \\
n=27\end{array}$ & $\begin{array}{l}\text { Survival group } \\
n=57\end{array}$ & $P$ value \\
\hline Male/female & $19 / 8$ & $31 / 26$ & 0.123 \\
\hline Age (years) & $68.6 \pm 11.1$ & $61.6 \pm 11.1$ & 0.009 \\
\hline Diabetes, n (\%) & $14(51.85)$ & $14(24.56)$ & 0.014 \\
\hline $\begin{array}{l}\text { Cardiovascular history, } \\
\text { n (\%) }\end{array}$ & $21(77.78 \%)$ & $19(33.33 \%)$ & 0.002 \\
\hline $\mathrm{BMI}\left(\mathrm{kg} / \mathrm{m}^{2}\right)$ & $22.92 \pm 3.35$ & $23.9 \pm 3.29$ & 0.213 \\
\hline Systolic BP (mmHg) & $152 \pm 25$ & $146 \pm 14$ & 0.278 \\
\hline Diastolic BP (mmHg) & $77 \pm 15$ & $80 \pm 9$ & 0.337 \\
\hline Dialysis vintage (months) & $51.0(35.8-80.6)$ & $63.6(24.8-88.45)$ & 0.723 \\
\hline CIMT (mm) & $1.51 \pm 0.40$ & $1.27 \pm 0.37$ & 0.011 \\
\hline Plaque, n (\%) & 25 (92.59) & $43(75.44)$ & 0.053 \\
\hline Sclerostin (pmol/L) & $217.30(141.37-239.73)$ & $152.34(111.80-201.15)$ & 0.042 \\
\hline PTH (pg/mL) & $482.00(264.00-650.00)$ & $489.00(243.50-911.50)$ & 0.438 \\
\hline s-klotho (U/L) & $42.45(28.03-61.52)$ & $41.21(28.21-74.91)$ & 0.730 \\
\hline Hemoglobin (g/L) & $112.00(96.00-122.00)$ & $115.00(108.50-125.00)$ & 0.237 \\
\hline Albumin $(\mathrm{g} / \mathrm{L})$ & $40(38-42)$ & $41(40-42)$ & 0.060 \\
\hline Creatinine $(\mu \mathrm{mol} / \mathrm{L})$ & $864.85 \pm 220.10$ & $949.19 \pm 272.83$ & 0.164 \\
\hline Uric acid $(\mu \mathrm{mol} / \mathrm{L})$ & $361.93 \pm 60.30$ & $406.65 \pm 91.25$ & 0.023 \\
\hline Phosphate (mmol/L) & $1.80 \pm 0.53$ & $1.80 \pm 0.53$ & 0.966 \\
\hline Calcium (mmol/L) & $2.13 \pm 0.22$ & $2.23 \pm 0.22$ & 0.064 \\
\hline Cholesterol (mmol/L) & $4.00 \pm 0.91$ & $4.31 \pm 0.91$ & 0.156 \\
\hline LDL-C (mmol/L) & $2.15 \pm 0.60$ & $2.38 \pm 0.68$ & 0.139 \\
\hline $\mathrm{HDL}-\mathrm{C}(\mathrm{mmol} / \mathrm{L})$ & $1.02 \pm 0.25$ & $1.03 \pm 0.29$ & 0.929 \\
\hline Alkaline phosphatase $(\mathrm{U} / \mathrm{L})$ & $104.00(79.00-161.00)$ & $99.00(73.50-126.50)$ & 0.294 \\
\hline KT/UV & $1.30 \pm 0.32$ & $1.33 \pm 0.30$ & 0.722 \\
\hline hs-CRP (mg/L) & $3.18(1.86-9.27)$ & $2.85(1.51-6.47)$ & 0.449 \\
\hline
\end{tabular}

Normally distributed variables are mean \pm standard deviation; non-normally distributed variables are median with 25 and $75 \%$ interquartile ranges in parentheses. CIMT carotid artery intima-media thickness, iPTH intact parathyroid hormone, sKlotho soluble klotho, $L D L-C$ low-density lipoprotein cholesterol, HDL-C high-density lipoprotein cholesterol, $H s$-CRP high-sensitivity C-reactive protein

mature osteocyte-like cells [23]. Sclerostin is mainly derived from osteocytes, and it is speculated that elevated serum sclerostin might be partly derived from calcified vasculature [13]. Recently, human atherosclerotic sites were shown to display sclerostin deposition detectable by immunohistochemistry [3]. Recent clinical studies revealed that serum sclerostin levels are higher in patients with carotid artery atherosclerotic plaques undergoing MHD, with sclerostin independently associated with CIMT [24]. These findings corroborated the present results. Nevertheless, the exact biological significance of high sclerostin levels are currently unknown and the threshold for considering sclerostin levels high in patients with CKD is currently not defined $[5,25]$. Nevertheless, it is known that sclerostin is a major player in the kidney-bone-vasculature axis and that it is involved in calcifications. Further in vivo studies are necessary to determine its exact role in atherosclerosis and the involvement of the Wnt- $\beta$-cathenin axis in the process [5].

The term "klotho" refers to a-klotho, which has two main types: membrane and soluble (the most abundant in humans) [26]. In cultured rat vascular smooth muscle cells (VSMCs), s-klotho controls cell differentiation and dedifferentiation by regulating the smooth muscle cell marker protein 22-a (SM22-a) and the mineralization marker Runx2, with a direct inhibitory effect on soft tissue calcification [26]. Clinical studies have also shown that serum klotho levels are inversely associated with the severity of coronary artery disease in patients with normal kidney function and abdominal aortic calcification (AAC) undergoing MHD [27, 28]. In this study, we found that sclerostin was inversely associated with s-klotho. Taken together, these findings suggest that vascular calcification is negatively associated with serum 


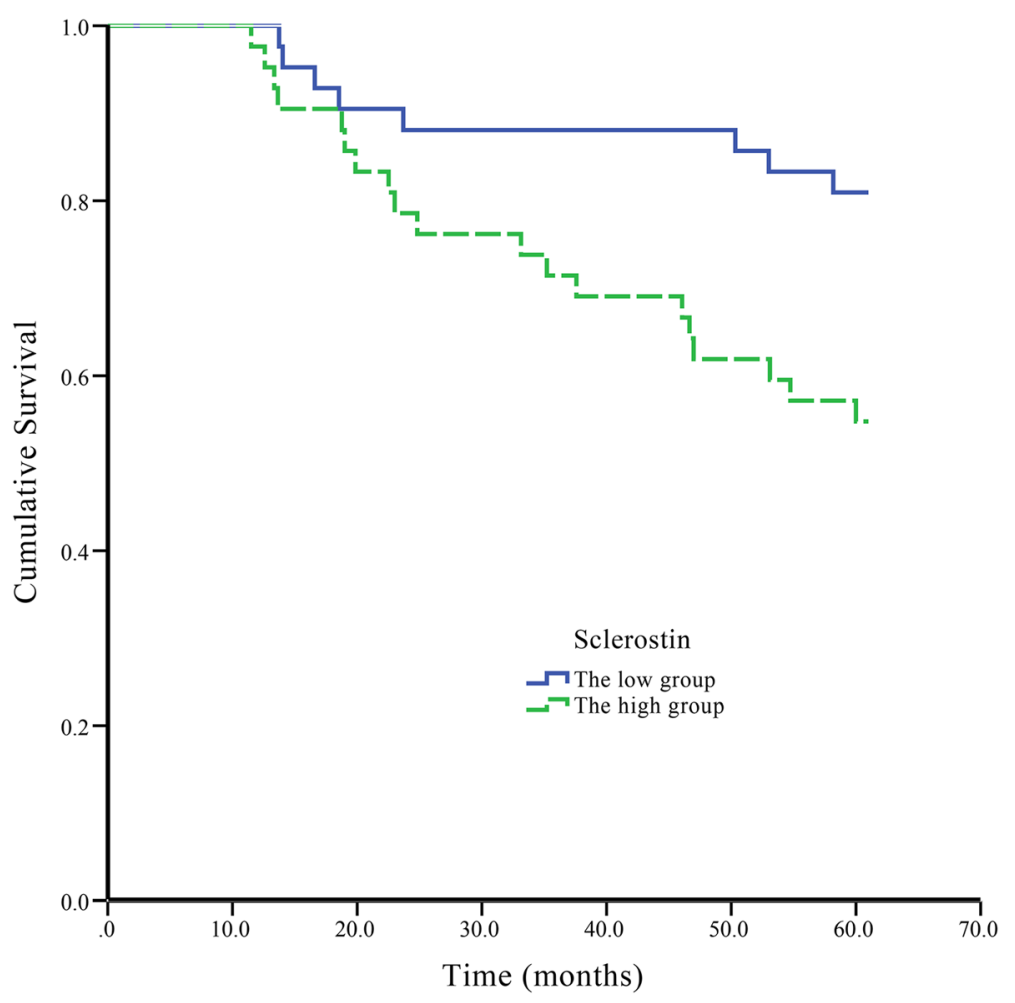

Fig. 1 Kaplan-Meier survival curves of all-cause mortality for the low and high sclerostin groups. (Log rank $p=0.011$ )

Table 3 Univariate and multivariate analysis for all-cause death in patients undergoing maintenance hemodialysis

\begin{tabular}{|c|c|c|c|}
\hline Variable & $\mathrm{HR}$ & $95.0 \% \mathrm{Cl}$ & $P$ value \\
\hline \multicolumn{4}{|l|}{ Univariate analysis } \\
\hline Age (per year) & 1.046 & $1.010-1.085$ & 0.013 \\
\hline Diabetes ( $\mathrm{Y}$ versus $\mathrm{N}$ ) & 2.760 & $1.293-5.892$ & 0.009 \\
\hline Cardiovascular history ( $\mathrm{Y}$ versus $\mathrm{N}$ ) & 3.895 & $1.570-9.666$ & 0.003 \\
\hline Hemoglobin (1 g/L) & 0.985 & $0.960-1.009$ & 0.221 \\
\hline Creatinine $(1 \mu \mathrm{mol} / \mathrm{L})$ & 0.999 & 0998-1.000 & 0.143 \\
\hline Uric acid $(1 \mu \mathrm{mol} / \mathrm{L})$ & 0.995 & $0.990-1.000$ & 0.033 \\
\hline Albumin (1 g/L) & 0.775 & $0.649-0.925$ & 0.005 \\
\hline Phosphate (1 mmol/L) & 0.993 & $0.477-2.066$ & 0.984 \\
\hline $\mathrm{Hs}-\mathrm{CRP}$ (1 mg/L) & 1.044 & $0.968-1.126$ & 0.263 \\
\hline Sclerostin (10 pmol/L) & 1.068 & $1.000-1.140$ & 0.049 \\
\hline IMT (0.1mm) & 1.154 & $1.049-1.269$ & 0.003 \\
\hline PTH (1 pg/mL) & 1.000 & $0.999-1.000$ & 0.431 \\
\hline Alkaline phosphatase (1 U/L) & 1.000 & $0.998-1.002$ & 0.934 \\
\hline Plaque ( $\mathrm{Y}$ versus $\mathrm{N}$ ) & 3.559 & $0.843-15.033$ & 0.084 \\
\hline \multicolumn{4}{|l|}{ Multivariate analysis } \\
\hline \multicolumn{4}{|l|}{ All-cause mortality } \\
\hline Sclerostin (10 pmol/L) & 1.095 & $1.022-1.174$ & 0.010 \\
\hline Albumin (1 g/L) & 0.742 & $0.612-0.900$ & 0.002 \\
\hline
\end{tabular}

Table 4 Univariate and multivariate analysis of cardiovascular death in patients undergoing maintenance hemodialysis

\begin{tabular}{|c|c|c|c|}
\hline Variable & $\mathrm{HR}$ & $95.0 \% \mathrm{Cl}$ & $p$ \\
\hline \multicolumn{4}{|l|}{ Univariate analysis } \\
\hline Age (per year) & 1.072 & $1.022-1.124$ & 0.004 \\
\hline Diabetes ( $(Y$ versus $N$ ) & 3.185 & $1.252-8.105$ & 0.015 \\
\hline Sex (Male versus Female) & 2.547 & $0.838-7.740$ & 0.099 \\
\hline Hemoglobin (1 g/L) & 1.005 & $0.971-1.039$ & 0.794 \\
\hline Creatinine $(1 \mu \mathrm{mol} / \mathrm{L})$ & 0.999 & $0997-1.001$ & 0.395 \\
\hline Uric acid (1 $\mu \mathrm{mol} / \mathrm{L})$ & 0.995 & $0.985-1.000$ & 0.072 \\
\hline Albumin (1 g/L) & 0.837 & $0.672-1.042$ & 0.111 \\
\hline Phosphate (1 mmol/L) & 0.914 & $0.370-2.257$ & 0.845 \\
\hline $\mathrm{Hs}-\mathrm{CRP}$ (1 mg/L) & 1.006 & $0.907-1.116$ & 0.907 \\
\hline Sclerostin (10 pmol/L) & 1.060 & $0.993-1.167$ & 0.074 \\
\hline I MT (0.1mm) & 1.208 & $1.077-1.355$ & 0.001 \\
\hline PTH (1 pg/mL) & 0.999 & $0.998-1.000$ & 0.159 \\
\hline Alkaline phosphatase (1 U/L) & 1.000 & $0.998-1.002$ & 0.903 \\
\hline Plaque ( $\mathrm{Y}$ versus $\mathrm{N}$ ) & 29.64 & $0.248-3536.44$ & 0.165 \\
\hline \multicolumn{4}{|l|}{ Multivariate analysis } \\
\hline \multicolumn{4}{|l|}{ Cardiovascular mortality } \\
\hline IMT (0.1mm) & 1.158 & $1.017-1.320$ & 0.027 \\
\hline Age (per year) & 1.063 & $1.011-1.118$ & 0.016 \\
\hline
\end{tabular}


s-klotho and positively correlated with serum sclerostin concentrations.

As shown above, patients with low baseline sclerostin levels had higher survival rate compared with those of the high sclerostin group, consistent with previous findings in non-dialysis CKD and MHD patients [18-20]. The association of sclerostin with mortality may reflect its role in vascular calcification. Studies in the CKD-2 mouse model support this notion; indeed, CKD-2 mice have higher levels of DKK1 (another Wnt-signaling inhibitor) and sclerostin amounts compared with non-CKD controls, and DKK1 inhibition by a monoclonal antibody ameliorates vascular calcification and decreases sclerostin levels [29]. Other investigators suggested that high serum sclerostin levels are associated with improved survival in patients undergoing MHD [16, 17]. High sclerostin in calcified vasculature may be a defensive response in order to limit further mineralization [30]. Some authors suggested the possibility that sclerostin has an anti-calcific effect by inhibiting ALP activity; ALP can inactivate inorganic pyrophosphate, and inorganic pyrophosphate is a potent inhibitor of calcification [31, 32]. Although sclerostin was shown above to be an independent predictor of all cause mortality, it was not associated with CV-related death, indicating that other mechanisms may be involved as well. The discrepant findings among studies assessing the role of sclerostin in patients undergoing MHD may be attributable to demographic characteristics (patients of different ethnicities), sample size (the lack of association may be due to insufficient sample size), or different sclerostin detection methods (sensitivity). Therefore, whether sclerostin is pro- or anti-calcification in the context of MHD remains unclear.

The current study showed that male patients had higher sclerostin levels than their female counterparts, corroborating previous studies [24, 33]. Possible explanations include higher bone mass (sclerostin is almost exclusively secreted by osteocytes) and lower estrogen levels (estrogens reduce serum sclerostin levels) in men [33]. Serum sclerostin is positively associated with age $[16,17,33]$. The present study found such a trend, but statistical significance was not reached; this may be attributed to the limited sample size.

Limitations of this study should be mentioned. First, the sample size was relatively small. In addition, it was a single-center study of a Chinese population. Therefore, the generalizability of the current findings to other ethnicities requires further validation. Finally, histomorphometric data of the bone were lacking.

\section{Conclusions}

In summary, sclerostin is related to atherosclerosis and all-cause mortality in patients undergoing MHD. Whether sclerostin is only a predictor or a significant risk factor for all-cause mortality remains unclear, and certainly worthy of further research.

\section{Additional file}

Additional file 1: Datasheet S1. Original dataset. (XLS 51 kb)

\section{Abbreviations}

AAC: Abdominal aortic calcification; AP: Alkaline phosphatase; AVC: Aortic valve calcification; Cl: Confidence interval; CIMTs: Carotid artery intima-media thicknesses; CKD-MBD: Chronic kidney disease-mineral bone disorder; ELISA: Enzyme-linked immunosorbent assay; GFR: Glomerular filtration rate; HDLC: High-density lipoprotein cholesterol; Hs-CRP: High-sensitivity C-reactive protein; IHC: Immunohistochemistry; LDL-C: Low-density lipoprotein cholesterol; MHD: Maintenance hemodialysis; P-MMA: Polymethylmethacrylate;

PS: Polysulfone; SD: Standard deviation; s-klotho: soluble klotho; SM22-a: Smooth muscle cell marker protein 22-a; VSMCs: Vascular smooth muscle cells

\section{Funding}

This study was supported by a grant from Beijing Municipal Commission of Science and Technology (Z151100004015083) to YM, and a grant from Beijing Hospital Nova Project (BJ-2016-034) to JC. The funding bodies had no role in study design, data collection, data interpretation, or manuscript writing.

Availability of data and materials

All data generated or analyzed during this study are included in this article. The original dataset is available as Additional file.

\section{Authors' contributions}

AC designed the experiments, performed the experiments, collected the data, performed the formal analysis and wrote the manuscript. YS, BZ, JC, HW, XC and YM performed the experiments and collected the data. YS, BZ and $\mathrm{YM}$ designed experiments. BZ and YM designed experiments and reviewed/edited the manuscript. All authors reviewed the results and approved the final version of the manuscript.

Ethics approval and consent to participate

The study was performed according to the Declaration of Helsinki and approved by the ethics committee of Beijing Hospital. Written informed consent was obtained from all patients. (Ethical approval number: 2016BJYYEC-110-01)

\section{Consent for publication}

Written informed consent was obtained from all patients.

Competing interests

The authors declare that they have no competing interests.

\section{Publisher's Note}

Springer Nature remains neutral with regard to jurisdictional claims in published maps and institutional affiliations.

\section{Author details}

${ }^{1}$ Department of Nephrology, Beijing Hospital, National Center of Gerontology, Beijing, People's Republic of China. ${ }^{2}$ The MOH Key Laboratory of Geriatrics, Beijing Hospital, National Center of Gerontology, Beijing, People's Republic of China.

Received: 11 August 2017 Accepted: 18 September 2018 Published online: 12 October 2018

\section{References}

1. Collins AJ, Foley RN, Chavers B, Gilbertson D, Herzog C, Johansen K, et al. United States renal data system 2011 annual data report: atlas of chronic kidney disease \& end-stage renal disease in the United States. Am J Kidney Dis. 2012;59(A7):e1-420.

2. Remppis A, Ritz E. Cardiac problems in the dialysis patient: beyond coronary disease. Semin Dial. 2008;21:319-25. 
3. Brandenburg VM, D'Haese P, Deck A, Mekahli D, Meijers B, Neven E, et al. From skeletal to cardiovascular disease in 12 steps-the evolution of sclerostin as a major player in CKD-MBD. Pediatr Nephrol. 2016;31:195-206.

4. Johnson ML, Rajamannan N. Diseases of Wnt signaling. Rev Endocr Metab Disord. 2006;7:41-9.

5. Evenepoel $P, D^{\prime}$ Haese $P$, Brandenburg V. Sclerostin and DKK1: new players in renal bone and vascular disease. Kidney Int. 2015;88:235-40.

6. Kubota T, Michigami T, Ozono K. Wnt signaling in bone. Clin Pediatr Endocrinol. 2010;19:49-56.

7. Moester MJ, Papapoulos SE, Lowik CW, van Bezooijen RL. Sclerostin: current knowledge and future perspectives. Calcif Tissue Int. 2010;87:99-107.

8. Pelletier S, Dubourg L, Carlier MC, Hadj-Aissa A, Fouque D. The relation between renal function and serum sclerostin in adult patients with CKD Clin J Am Soc Nephrol. 2013;8:819-23.

9. Bonani M, Rodriguez D, Fehr T, Mohebbi N, Brockmann J, Blum M, et al Sclerostin blood levels before and after kidney transplantation. Kidney Blood Press Res. 2014;39:230-9.

10. Sabbagh Y, Graciolli FG, O'Brien S, Tang W, dos Reis LM, Ryan S, et al. Repression of osteocyte Wnt/beta-catenin signaling is an early event in the progression of renal osteodystrophy. J Bone Miner Res. 2012;27:1757-72.

11. Dejana E. The role of wnt signaling in physiological and pathological angiogenesis. Circ Res. 2010;107:943-52.

12. Marinou K, Christodoulides C, Antoniades C, Koutsilieris M. Wnt signaling in cardiovascular physiology. Trends Endocrinol Metab. 2012;23:628-36.

13. Brandenburg VM, Kramann R, Koos R, Kruger T, Schurgers L, Muhlenbruch G, et al. Relationship between sclerostin and cardiovascular calcification in hemodialysis patients: a cross-sectional study. BMC Nephrol. 2013;14:219.

14. Kramann R, Brandenburg VM, Schurgers LJ, Ketteler M, Westphal S, Leisten I, et al. Novel insights into osteogenesis and matrix remodelling associated with calcific uraemic arteriolopathy. Nephrol Dial Transplant. 2013;28:856-68.

15. Koos R, Brandenburg V, Mahnken AH, Schneider R, Dohmen G, Autschbach $R$, et al. Sclerostin as a potential novel biomarker for aortic valve calcification: an in-vivo and ex-vivo study. J Heart Valve Dis. 2013;22:317-25.

16. Viaene L, Behets GJ, Claes K, Meijers B, Blocki F, Brandenburg V, et al. Sclerostin: another bone-related protein related to all-cause mortality in haemodialysis? Nephrol Dial Transplant. 2013;28:3024-30.

17. Drechsler C, Evenepoel P, Vervloet MG, Wanner C, Ketteler M, Marx N, et al. High levels of circulating sclerostin are associated with better cardiovascular survival in incident dialysis patients: results from the NECOSAD study. Nephrol Dial Transplant. 2015;30:288-93.

18. Desjardins L, Liabeuf S, Oliveira RB, Louvet L, Kamel S, Lemke HD, et al. Uremic toxicity and sclerostin in chronic kidney disease patients. Nephrol Ther. 2014;10:463-70.

19. Goncalves FL, Elias RM, dos Reis LM, Graciolli FG, Zampieri FG, Oliveira RB, et al. Serum sclerostin is an independent predictor of mortality in hemodialysis patients. BMC Nephrol. 2014;15:190

20. Kanbay M, Siriopol D, Saglam M, Kurt YG, Gok M, Cetinkaya H, et al. Serum sclerostin and adverse outcomes in nondialyzed chronic kidney disease patients. J Clin Endocrinol Metab. 2014;99:E1854-61.

21. Sun Y, Chen A, Wang C, Li C, Mao Y, Wu H. Associations of carotid intimamedia thickness with HsCRP, FGF23 and klotho in Chinese maintenance hemodialysis patients. Chinese Journal of Blood Purification. 2014;13:17-22.

22. Boulos NM, Gardin JM, Malik S, Postley J, Wong ND. Carotid plaque characterization, stenosis, and intima-media thickness according to age and gender in a large registry cohort. Am J Cardiol. 2016;117:1185-91.

23. Shanahan CM, Crouthamel MH, Kapustin A, Giachelli CM. Arterial calcification in chronic kidney disease: key roles for calcium and phosphate. Circ Res. 2011;109:697-711.

24. Kirkpantur A, Balci M, Turkvatan A, Afsar B. Independent association between serum sclerostin levels and carotid artery atherosclerosis in prevalent haemodialysis patients. Clin Kidney J. 2015;8:737-43.

25. Delanaye P, Paquot F, Bouquegneau A, Blocki F, Krzesinski JM, Evenepoel P, et al. Sclerostin and chronic kidney disease: the assay impacts what we (thought to) know. Nephrol Dial Transplant. 2017.

26. Hu MC, Shi M, Zhang J, Quinones H, Griffith C, Kuro-o M, et al. Klotho deficiency causes vascular calcification in chronic kidney disease. J Am Soc Nephrol. 2011;22:124-36.

27. Navarro-Gonzalez JF, Donate-Correa J, Muros de Fuentes M, PerezHernandez H, Martinez-Sanz R, Mora-Fernandez C. Reduced klotho is associated with the presence and severity of coronary artery disease. Heart. 2014;100:34-40.
28. Cai H, Lu R, Zhang M, Pang H, Zhu M, Zhang W, et al. Serum soluble klotho level is associated with abdominal aortic calcification in patients on maintenance hemodialysis. Blood Purif. 2015;40:120-6.

29. Fang $Y$, Ginsberg $C$, Seifert M, Agapova O, Sugatani T, Register TC, et al. CKD-induced wingless/integration1 inhibitors and phosphorus cause the CKD-mineral and bone disorder. J Am Soc Nephrol. 2014;25:1760-73.

30. Zhu D, Mackenzie NC, Millan JL, Farquharson C, MacRae VE. The appearance and modulation of osteocyte marker expression during calcification of vascular smooth muscle cells. PLoS One. 2011;6:e19595.

31. Towler DA. Inorganic pyrophosphate: a paracrine regulator of vascular calcification and smooth muscle phenotype. Arterioscler Thromb Vasc Biol. 2005;25:651-4

32. Devarajan-Ketha H, Craig TA, Madden BJ, Robert Bergen H 3rd, Kumar R. The sclerostin-bone protein interactome. Biochem Biophys Res Commun. 2012:417:830-5.

33. Modder UI, Hoey KA, Amin S, McCready LK, Achenbach SJ, Riggs BL, et al. Relation of age, gender, and bone mass to circulating sclerostin levels in women and men. J Bone Miner Res. 2011;26:373-9.

\section{Ready to submit your research? Choose BMC and benefit from:}

- fast, convenient online submission

- thorough peer review by experienced researchers in your field

- rapid publication on acceptance

- support for research data, including large and complex data types

- gold Open Access which fosters wider collaboration and increased citations

- maximum visibility for your research: over $100 \mathrm{M}$ website views per year

At BMC, research is always in progress.

Learn more biomedcentral.com/submissions 